\title{
Growth of multiwall carbon nanocoils using Fe catalyst films prepared by ion sputtering - ERRATUM
}

Dawei Li, Lujun Pan, Kun Liu, Wei Peng, and Rashad Muhammad

doi: 10.1557/jmr.2013.107, Published by Cambridge University Press, 26 April 2013.

In Li et al. ${ }^{1}$, Figs. $2-5$ are incorrectly ordered and labeled.

The publisher regrets the mistake.

\section{REFERENCE}

1. D. Li, L. Pan, K. Liu, W. Peng, and R. Muhammad: Growth of multiwall carbon nanocoils using Fe catalyst filmsprepared by ion sputtering. J. Mater. Res. 28(10), 1316-1325 (2013). 


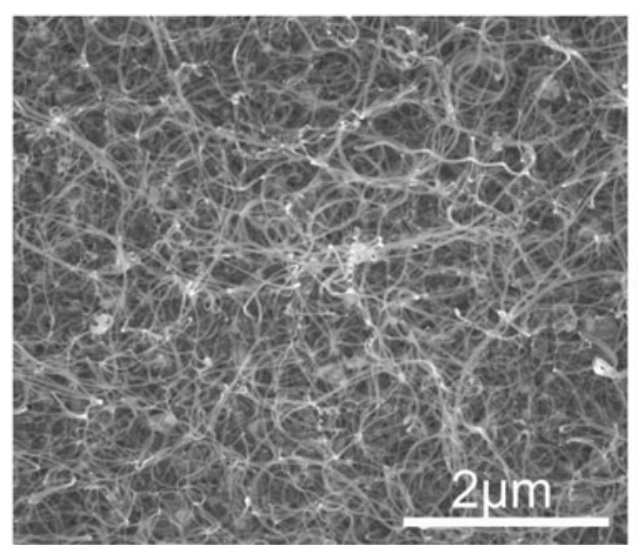

(a)

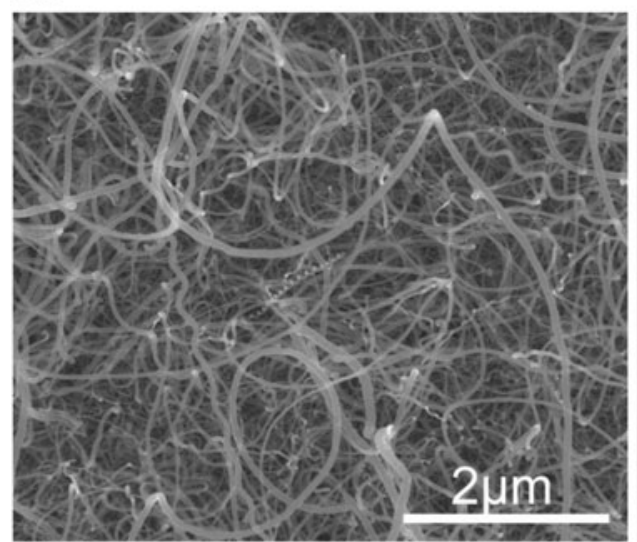

(c)

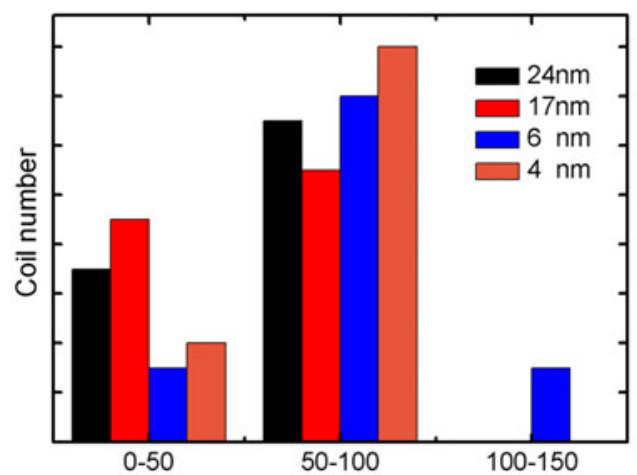

(e)

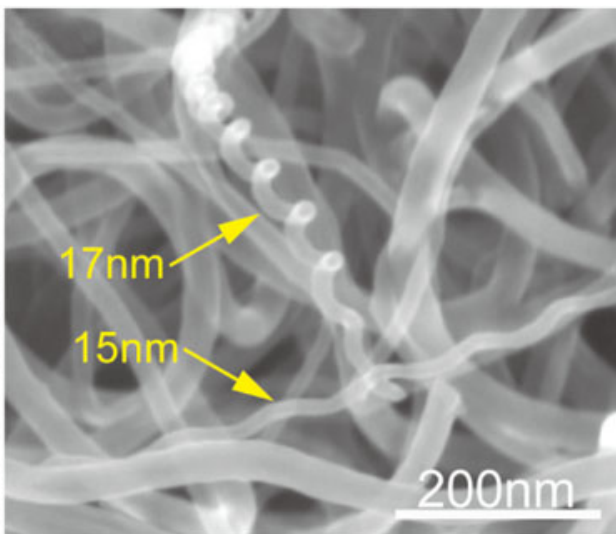

(b)

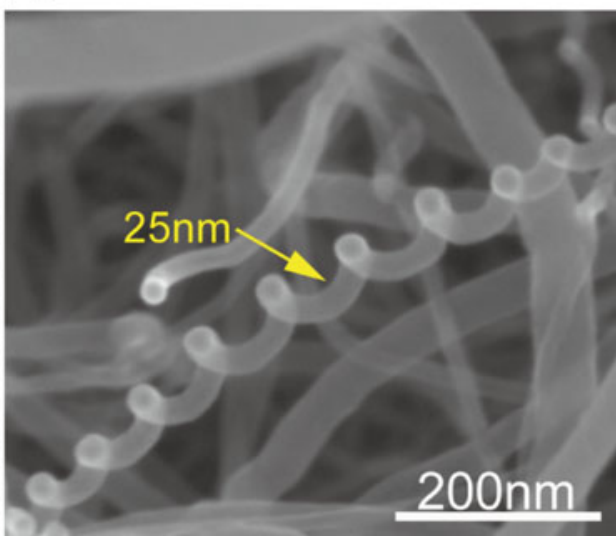

(d)

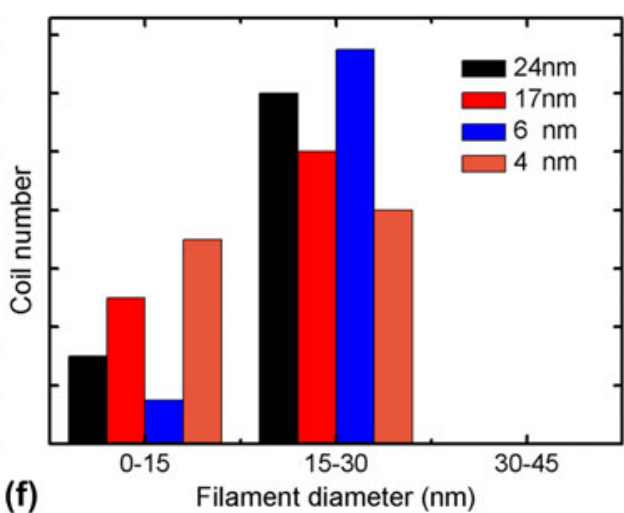

FIG. 2. Typical SEM images of the carbon deposits synthesized at $700{ }^{\circ} \mathrm{C}$ using $\mathrm{Fe}$ film catalysts deposited on $\mathrm{SiO}_{2}$ substrates by ion sputtering. (a) $24 \mathrm{~nm}$ and (c) $6 \mathrm{~nm}$. (b) and (d) are the corresponding enlarged images of MWCNCs in (a) and (c). (e) and (f) show distributions of coil diameters and filament diameters of MWCNCs prepared using $\mathrm{Fe}$ films deposited on $\mathrm{SiO}_{2}$ substrates with different film thickness. 


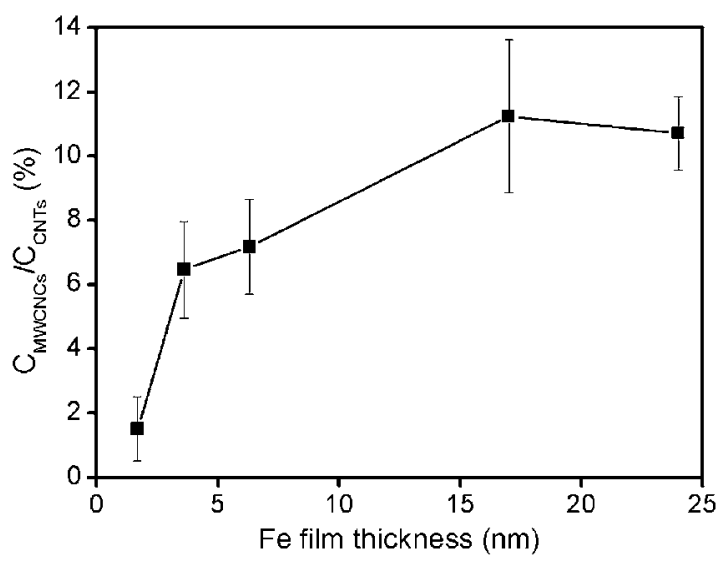

FIG. 3. Dependence of the MWCNCs and CNTs ratio with Fe film thickness.

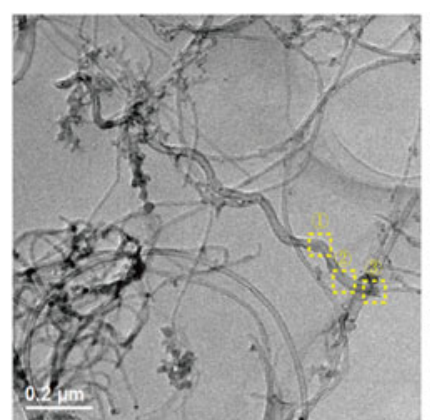

(a)

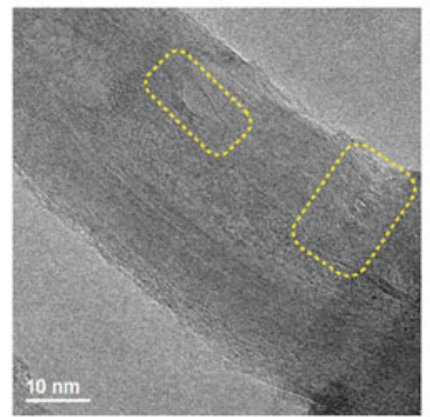

(c)

FIG. 4. (a) Typical TEM image of the MWCNC synthesized using 17-nm-thick $\mathrm{Fe}$ film catalyst deposited on $\mathrm{SiO}_{2}$ substrate. (b-d) The corresponding HRTEM images of MWCNC of parts 1,2 and 3 shown in (a).

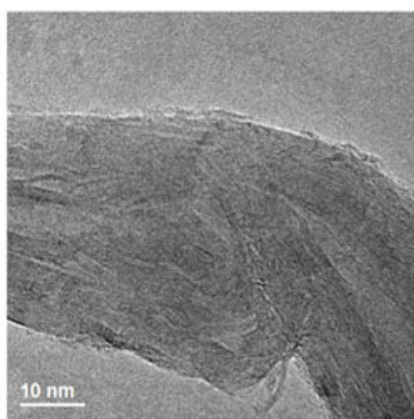

(b)

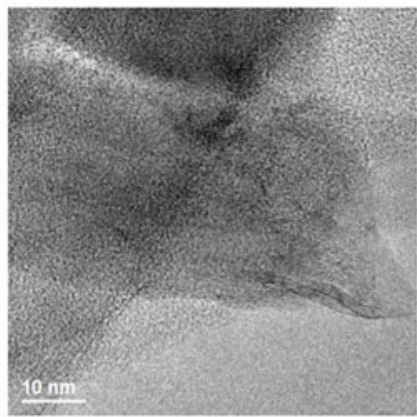

(d) 


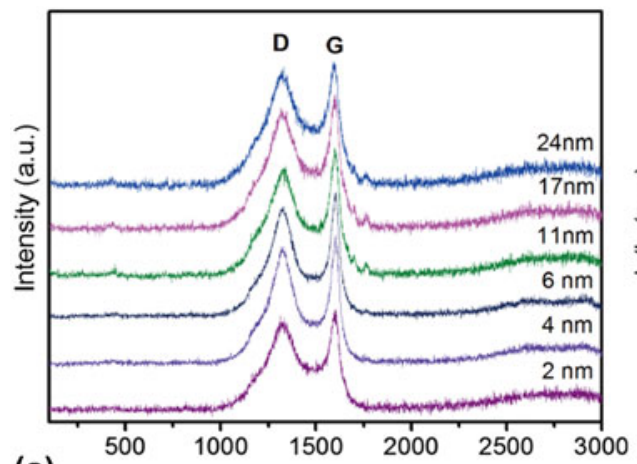

(a)

Raman shift $\left(\mathrm{cm}^{-1}\right)$
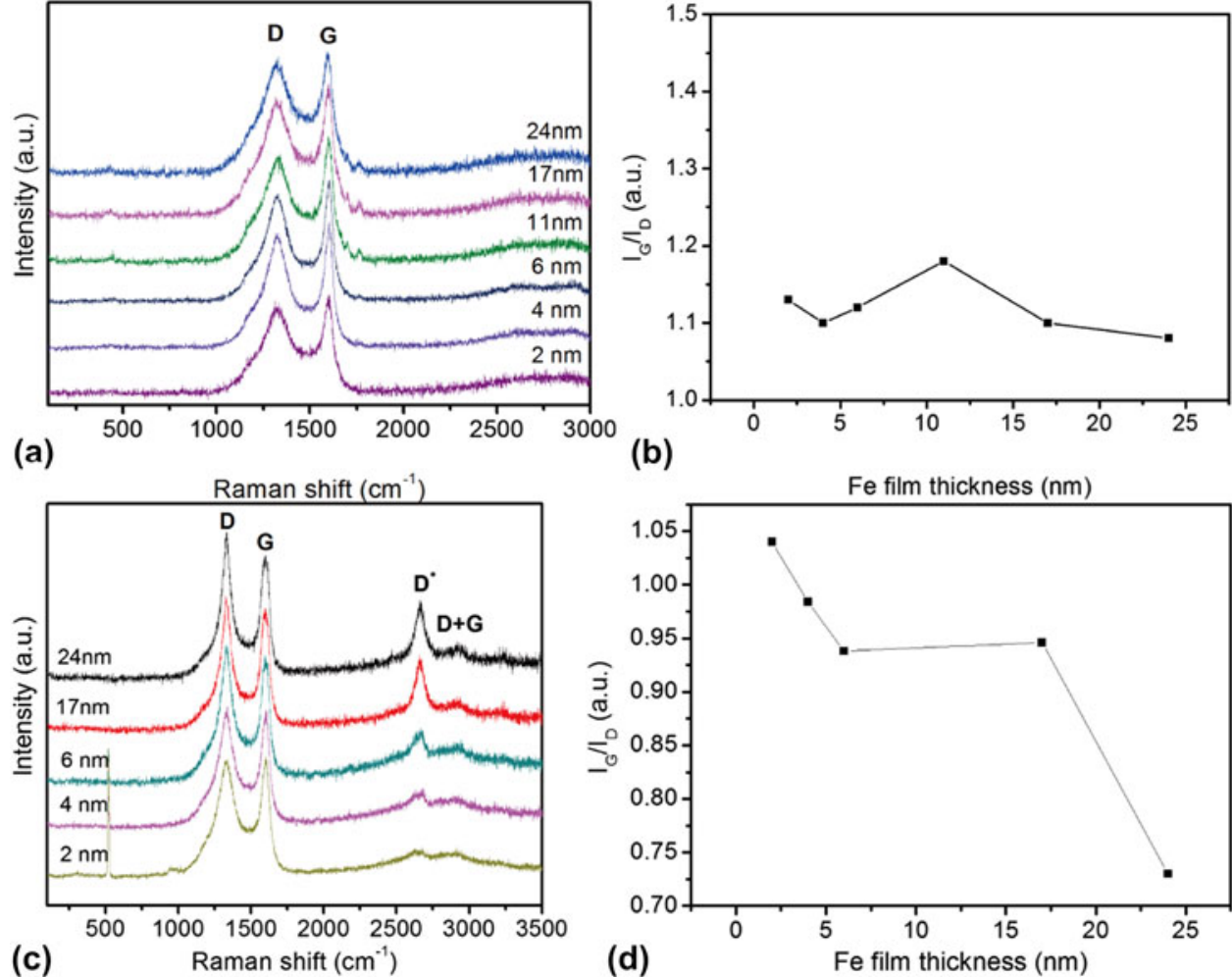

(b)

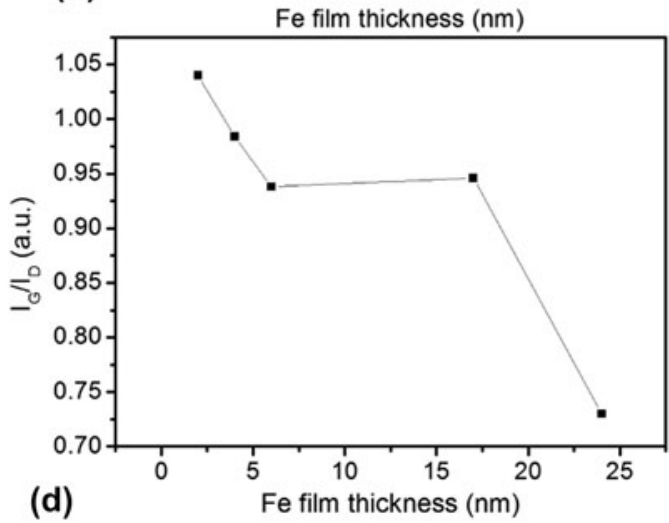

FIG. 5. Raman spectra of carbon deposits prepared using Fe films deposited on (a) ITO and (c) $\mathrm{SiO}_{2}$ substrates with different film thickness. (b) and (d) show the corresponding variation of IG/ID ratio with Fe film thickness shown in (a) and (c). 